J. Dairy Sci. 98:2515-2528

http://dx.doi.org/10.3168/jds.2014-9058

(C) American Dairy Science Association ${ }^{\circledR}, 2015$.

\title{
Progesterone supplementation to lactating dairy cows without a corpus luteum at initiation of the Ovsynch protocol
}

\author{
R. S. Bisinotto, L. O. Castro, M. B. Pansani, C. D. Narciso, N. Martinez, L. D. P. Sinedino, T. L. C. Pinto, \\ N. S. Van de Burgwal, H. M. Bosman, R. S. Surjus, W. W. Thatcher, and J. E. P. Santos ${ }^{1}$ \\ Department of Animal Sciences, D. H. Barron Reproductive and Perinatal Biology Research Program, University of Florida, Gainesville 32611
}

\begin{abstract}
The objectives were to determine the effect of progesterone supplementation on fertility responses in lactating dairy cows without corpora lutea (CL) at initiation of the timed artificial insemination (AI) program. Holstein cows from 5 commercial dairy farms were subjected to the Ovsynch-56 protocol (d $-10 \mathrm{GnRH}, \mathrm{d}-3$ $\left.\mathrm{PGF}_{2 \alpha}, \mathrm{d}-0.7 \mathrm{GnRH}, \mathrm{d} 0 \mathrm{AI}\right)$. Ovaries were scanned by ultrasonography on $\mathrm{d}-10$. Within farm, cows without CL were blocked by pen and assigned randomly to remain as nonsupplemented controls $(\mathrm{CON} ; \mathrm{n}=$ 652 ) or to receive 2 controlled internal drug-release (CIDR) inserts containing $1.38 \mathrm{~g}$ of progesterone each from $\mathrm{d}-10$ to -3 (2CIDR; $\mathrm{n}=642$ ). Cows with CL were randomly selected within pen and used as positive controls as cows in diestrus at the initiation of the Ovsynch protocol (DIEST; $\mathrm{n}=640$ ). Signs of estrus were detected beginning on $\mathrm{d}-9$ based on removal of tail chalk, and cows in estrus received AI on the same day. Blood samples from subsets of cows on $\mathrm{d}-10,-9$, $-7,-5,-3$, and $0(\mathrm{n}=109)$ and on $\mathrm{d} 6,13$, and 19 $(\mathrm{n}=156)$ were analyzed for progesterone concentrations. Pregnancy was diagnosed on d 32 and 60 after AI. The average progesterone concentration during the timed AI program was lowest for CON, intermediate for 2CIDR, and highest for DIEST $(0.92,2.77$, and 4.93 $\mathrm{ng} / \mathrm{mL}$, respectively). The proportions of cows that ovulated in response to the first $\mathrm{GnRH}$ (63.6, 61.1, and $47.2 \%$, respectively) and that had a new CL on $\mathrm{d}-3$ at $\mathrm{PGF}_{2 \alpha}$ injection $(72.4,67.9$, and $47.4 \%$, respectively) were greater for CON and 2CIDR compared with DIEST, respectively. The diameter of the ovulatory follicle and the proportion of cows that ovulated in response to the second GnRH did not differ among treatments. A greater proportion of CON and 2CIDR cows were detected in estrus at AI compared with DIEST cows $(35.8,39.6$, and $30.6 \%$, respectively). Pregnancy per AI
\end{abstract}

Received November 3, 2014.

Accepted December 13, 2014.

${ }^{1}$ Corresponding author: jepsantos@ufl.edu was less for CON compared with 2CIDR and DIEST on d $32(31.3,42.2$, and $38.4 \%$, respectively) and d 60 after AI $(28.9,37.2$, and $33.9 \%$, respectively), indicating that progesterone supplementation reestablished fertility in cows lacking a CL similar to that of cows in diestrus at the initiation of the timed AI program. Treatment did not affect pregnancy loss between d 32 and 60 of gestation. Pregnancy from a subset of cows with plasma progesterone concentrations indicated that a minimum concentration of $2.0 \mathrm{ng} / \mathrm{mL}$ was needed to optimize fertility. A single ultrasound examination effectively identified a low-fertility cohort of cows based on the absence of CL at the first GnRH injection of the Ovsynch protocol. Supplementation with 2 CIDR inserts increased progesterone in plasma by an additional $1.85 \mathrm{ng} / \mathrm{mL}$ compared with $\mathrm{CON}$, resulting in concentrations of $2.77 \mathrm{ng} / \mathrm{mL}$ during development of the ovulatory follicle, which restored fertility in dairy cows lacking CL to a level similar to that of cows in diestrus.

Key words: anovular cow, corpus luteum, progesterone, reproduction

\section{INTRODUCTION}

Timed AI programs have contributed to the increase in reproductive performance observed in US dairy herds over the past decade (Bisinotto et al., 2014). In addition to maximizing insemination rates, timed AI programs provide a unique opportunity for identification of low-fertility cohorts of cows and the implementation of strategies to improve pregnancy per AI (P/AI). For instance, cows without a mature corpus luteum (CL) at initiation of the synchronization protocol have insufficient concentrations of progesterone in plasma to support proper growth of the ovulatory follicle, which is considered a major impediment for fertility in highproducing dairy cows (Wiltbank et al., 2011; Bisinotto et al., 2014). Suboptimal concentrations of progesterone in plasma during the estrous cycle preceding ovulation alter uterine gland morphology (Shaham-Albalancy et al., 1997) and increase $\mathrm{PGF}_{2 \alpha}$ synthesis in response to 
oxytocin in the subsequent diestrus (Shaham-Albalancy et al., 2001; Cerri et al., 2011), all of which might threaten the establishment of pregnancy. In addition to effects on the endometrium, low concentrations of progesterone have been associated with increased $\mathrm{LH}$ pulsatility (Endo et al., 2012) and rate of growth of the ovulatory follicle (Cerri et al., 2011), reduced follicular fluid concentrations of IGF-1 (Cerri et al., 2011), impaired embryo quality on d 7 after AI (Rivera et al., 2011), and reduced P/AI (Bisinotto et al., 2013).

In herds that use timed AI for management of reproduction, the cohort of cows with low concentrations of progesterone during follicular development can be identified using a single ultrasound examination of the ovaries performed at the beginning of the synchronization protocol (Bisinotto et al., 2013). Cows without a CL at initiation of the 5-d timed AI program, which encompasses anovular cows and cyclic cows not in diestrus, were $40 \%$ less likely to become pregnant compared with herdmates in diestrus (Bisinotto et al., 2013). This reduction in $\mathrm{P} / \mathrm{AI}$ has major implications for reproductive performance in dairy herds because approximately $30 \%$ of the cows receiving the first AI postpartum (Stevenson et al., 2008; Bisinotto et al., 2010) and 22 to $46 \%$ of those receiving resynchronized AI (Fricke et al., 2003; Silva et al., 2009) lack a CL when synchronization is initiated. However, commercially available systems for delivery of progesterone are not optimized for high-producing dairy cows and have yielded variable results when used in cows lacking CL (Bisinotto and Santos, 2011). Controlled internal drugrelease (CIDR) inserts supply approximately $89 \mathrm{mg}$ of progesterone daily (Rathbone et al., 2002), which increases concentrations of progesterone in plasma by $0.8 \mathrm{ng} / \mathrm{mL}$ in high-producing cows during a 7-d period (Cerri et al., 2009a). Such increments are well below the observed concentrations of progesterone of cows in diestrus. Alternatively, treating cows without CL with 2 intravaginal inserts during the 5 -d timed AI program increased circulating concentrations of progesterone by $2.1 \mathrm{ng} / \mathrm{mL}$ and restored P/AI to a level similar to that of cows in diestrus (Bisinotto et al., 2013).

The Ovsynch protocol with $56 \mathrm{~h}$ of proestrus maintains a 7 -d interval between the initial $\mathrm{GnRH}$ and the injection of $\mathrm{PGF}_{2 \alpha}$ and is likely the most common timed AI program in countries where the use of estradiol in cattle is no longer allowed. The reduction in $\mathrm{P} / \mathrm{AI}$ when cows do not have a CL at initiation of the timed AI protocol is similar whether they are subjected to the Ovsynch protocol (Bisinotto et al., 2010) or to the 5-d timed AI protocol (Bisinotto et al., 2013). However, the efficacy of supplementing progesterone using 2 intravaginal inserts to cows without a CL at initiation of the Ovsynch protocol has not been critically evaluated. Incorporation of 2 CIDR inserts to the Cosynch protocol initiated in cows synchronized to be in proestrus or estrus marginally improved $\mathrm{P} / \mathrm{AI}$ compared with nonsupplemented controls (Denicol et al., 2012). The 2 additional days between the initial GnRH and the injection of $\mathrm{PGF}_{2 \alpha}$ in Cosynch compared with the 5-d timed AI protocol might affect the response to the amount of supplemental progesterone because of prolonged follicle growth, which might explain the lack of a clear benefit from increasing progesterone observed previously (Denicol et al., 2012). In addition, the Cosynch protocol, with $72 \mathrm{~h}$ of proestrus, is not ideal for high fertility, and inducing ovulation $16 \mathrm{~h}$ before timed AI improves $\mathrm{P} / \mathrm{AI}$ in the Ovsynch protocol (Brusveen et al., 2008). Therefore, the benefit of supplementing progesterone in adequate amounts to cows without a CL might increase when the timed AI protocol is optimized to adequate proestrus and timing of ovulation relative to AI. Because supplementing progesterone with 2 CIDR in cows without a CL in the 5-d timed AI protocol restored P/ AI similar to that of cows in diestrus, it is important to determine if such a response is also observed in cows undergoing the Ovsynch-56 protocol.

The hypothesis of the present study was that supplementing progesterone, using 2 intravaginal inserts, to increase concentrations of progesterone in plasma by approximately $2.0 \mathrm{ng} / \mathrm{mL}$ in lactating dairy cows lacking a CL at the initiation of the Ovsynch-56 protocol would restore fertility to a level similar to that of cows in diestrus. Specific objectives were to evaluate the effects of incorporating 2 intravaginal inserts containing progesterone to the Ovsynch-56 protocol on ovarian responses to the synchronization program, concentrations of progesterone in plasma, P/AI, and pregnancy loss in lactating dairy cows without a CL at the first GnRH injection.

\section{MATERIALS AND METHODS}

All procedures involving animals in this study were approved by the University of Florida IFAS Animal Research Committee. All reproductive hormones used in the experiment were purchased for the study.

\section{Cows and Housing}

The study was conducted in 5 commercial dairy farms: 4 located in Hanford, California (herds 1, 2, 3 , and 4) and 1 located in Trenton, Florida (herd 5). Cows were enrolled in the study from September 2013 to April 2014. A total of 4,000, 1,500, 1,800, 1,450, and 4,500 cows were milked in herds 1 through 5 at the 
initiation of the study, respectively. The yearly rolling herd averages for milk yield were approximately 12,700 $\mathrm{kg}$ for herds 1, 2, 3, and 4, and 11,000 $\mathrm{kg}$ for herd 5. Cows diagnosed with abnormal reproductive tracts (adhesions or abscesses in the uterus or ovaries) were not eligible for enrollment. Primiparous $(\mathrm{n}=733)$ and multiparous ( $\mathrm{n}=1,201)$ cows were housed separately in freestall barns equipped with sprinklers and fans in herds $1,2,3$, and 5 , or in dry lots provided with shades in herd 4. Pens in all herds had soakers for evaporative cooling in the feed lane. Cows were restrained in headlock stations during all experimental procedures.

\section{Reproductive Management}

All cows were subjected to the standard Ovsynch-56 protocol (Figure 1), in which 986 received the first postpartum AI and 948 were subjected to a resynchronized insemination after being diagnosed as nonpregnant. Cows receiving the first AI postpartum had their estrous cycle presynchronized with 2 i.m. injections of $\mathrm{PGF}_{2 \alpha}$ (Lutalyse sterile solution, $25 \mathrm{mg}$ of dinoprost tromethamine, Zoetis, Madison, NJ) administered $14 \mathrm{~d}$ apart, at $38 \pm 3$ and $52 \pm 3$ DIM (herds 1, 2 and 4) or at $44 \pm 3$ and $58 \pm 3$ DIM (herds 3 and 5 ). Cows not observed in estrus after the second $\mathrm{PGF}_{2 \alpha}$ were enrolled in the Ovsynch-56 protocol $11 \mathrm{~d}$ later. Cows receiving resynchronized inseminations were enrolled in the timed AI program following a nonpregnancy diagnosis at 35 $\pm 3 \mathrm{~d}$ after the previous insemination. The Ovsynch-56 protocol consisted of an i.m. injection of $\mathrm{GnRH}$ on study $\mathrm{d}-10$ (Cystorelin, $100 \mu \mathrm{g}$ of gonadorelin diacetate tetrahydrate equivalent to $86 \mu \mathrm{g}$ of gonadorelin, Merial Ltd., Duluth, GA) followed by an injection of $\mathrm{PGF}_{2 \alpha}$ on $\mathrm{d}-3$ and a second injection of GnRH $56 \mathrm{~h}$ later (d -0.7 ). Timed AI was performed $16 \mathrm{~h}$ after the second GnRH injection, which was considered study d 0. All cows had their tailheads painted daily with chalk (All Weather Paintstik, LA-CO Industries Inc., Elk Grove Village, IL) starting on $\mathrm{d}-10$, and removal of chalk was used as an indication of estrus. Cows detected in estrus from $\mathrm{d}-9$ to -1 were inseminated on the same day and did not receive any further treatment.

\section{Ultrasonography of the Ovaries and Treatments}

All cows had their ovaries evaluated by ultrasonography using a portable ultrasound equipped with a 7.5-MHz transrectal linear transducer (Easi-Scan, BCF Technology, Rochester, MN) on d -10 , and the loca-

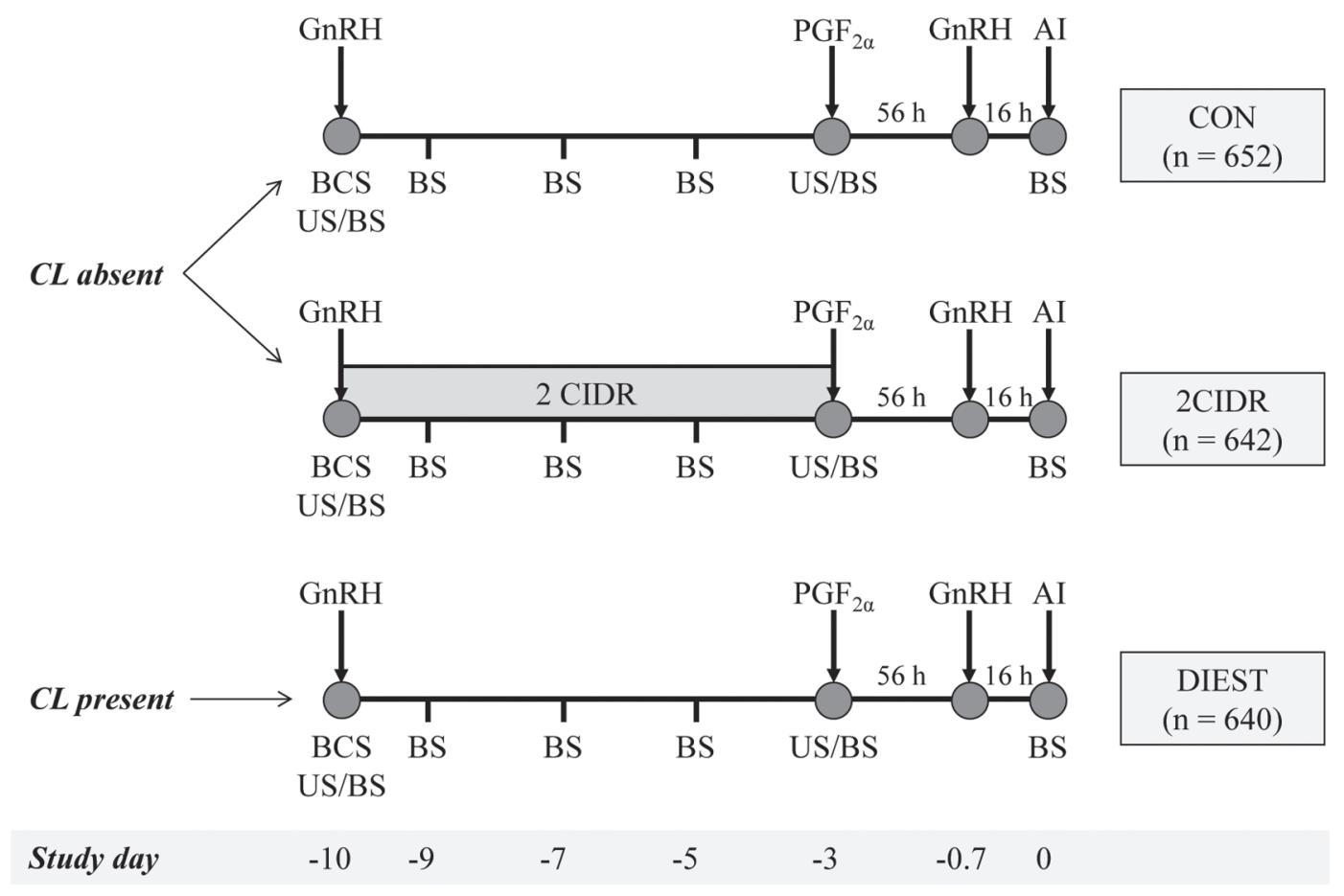

Figure 1. Diagram of activities and protocol for synchronization of the estrous cycle and timed AI. CON $=$ cows without CL on $d-10$ (control); $2 \mathrm{CIDR}=$ cows without CL on $\mathrm{d}-10$ and treated with 2 controlled internal drug release (CIDR) inserts containing $1.38 \mathrm{~g}$ of progesterone each from $\mathrm{d}-10$ to -3 ; DIEST = cows with CL on d -10 . BCS = scoring of body condition; BS = blood sampling for analyses of progesterone; $\mathrm{CL}=$ corpus luteum; US = ovarian ultrasonography. 
tions of CL and follicles $\geq 10 \mathrm{~mm}$ in diameter were recorded. Cows without CL were those in which no luteal structure was visualized or those with a luteal structure $<10 \mathrm{~mm}$ in diameter. Cows in diestrus were considered those with a CL $\geq 20 \mathrm{~mm}$ in diameter.

Cows without a CL were blocked by pen and allocated randomly into 1 of 2 treatments (Figure 1). Cows assigned to remain as untreated controls received no supplemental progesterone $(\mathbf{C O N}, \mathrm{n}=652)$. Cows assigned to receive progesterone supplementation were treated with 2 intravaginal inserts containing $1.38 \mathrm{~g}$ of progesterone each (Eazi-Breed CIDR Cattle Insert, Zoetis) from $\mathrm{d}-10$ to $-3(\mathbf{2 C I D R}, \mathrm{n}=642)$. Cows in diestrus were matched by pen and day of enrollment and used as positive controls (DIEST; $\mathrm{n}=640$ ) to evaluate the efficacy of progesterone supplementation in restoring fertility in cows without CL relative to that of cows in diestrus at the initiation of the timed AI program. The proportions of CON, 2CIDR, and DIEST cows receiving the first AI postpartum were $54.9,52.3$, and $45.6 \%$, respectively. People handled all hormones and intravaginal inserts wearing plastic palpation sleeves beneath latex gloves to prevent direct contact with skin. Used CIDR inserts were placed in sealable plastic bags and returned to the laboratory to be disposed of as biohazard at the University of Florida. In the United States, where the study was conducted, the CIDR insert is approved for use in lactating dairy cattle, with labels for induction of estrous cycle in anovular cows and synchronization of the return to estrus in previously inseminated cows. However, in many countries, the CIDR and other intravaginal inserts containing progesterone are approved for use in multiple manners, including as part of timed AI programs.

A second ultrasound evaluation of the ovaries was performed on $\mathrm{d}-3$ in all cows from herds $1,2,4$, and 5. Ovulation in response to the first GnRH was considered for cows that had a follicle $\geq 10 \mathrm{~mm}$ on $\mathrm{d}$ -10 and in which a new CL was observed in the same ovary on $\mathrm{d}-3$. Cows with follicles $<10 \mathrm{~mm}$ on study $\mathrm{d}-10$ but with a new CL on study $\mathrm{d}-3$ were considered to have a new CL but ovulated before study $\mathrm{d}-10$. A subset of 197 cows from herd $2(\mathrm{CON}, \mathrm{n}=$ 67; 2CIDR, $\mathrm{n}=67$; DIEST, $\mathrm{n}=63)$ had their ovaries scanned (Aloka SSD-500 equipped with a 7.5-MHz linear transducer, Aloka Co., Tokyo, Japan) on d -0.7 and 1, corresponding to the second GnRH injection and the day after timed AI, respectively. The diameter of all follicles $\geq 5 \mathrm{~mm}$ was measured. Ovulation to the second GnRH was defined as the disappearance of one or more follicles $\geq 10 \mathrm{~mm}$ in diameter within $40 \mathrm{~h}$ of the GnRH administration.

\section{Analysis of Progesterone Concentrations in Plasma}

Blood was sampled by puncture of coccygeal vessels into evacuated tubes containing $\mathrm{K}_{2}$ EDTA (Vacutainer; Becton Dickinson, Franklin Lakes, NJ) to quantify progesterone concentrations during the Ovsynch-56 protocol $(\mathrm{d}-10,-9,-7,-5,-3$, and $0 ; \mathrm{CON}, \mathrm{n}=37$; 2CIDR, $\mathrm{n}=38$; DIEST, $\mathrm{n}=34$ ). Another 26 2CIDR cows had blood sampled on $\mathrm{d}-9,-7,-5$, and -3 to determine the minimum concentration of progesterone during the growth of the ovulatory follicle that optimizes P/AI $(\mathrm{n}=64)$. Finally, concentrations of progesterone after AI were measured on d 6, 13, and $19(\mathrm{CON}, \mathrm{n}=56 ; 2$ CIDR, $\mathrm{n}=56$; DIEST, $\mathrm{n}=57$ ). Blood tubes were placed in ice immediately after collection and centrifuged at $2,000 \times g$ for $15 \mathrm{~min}$ at $4^{\circ} \mathrm{C}$ for plasma separation within $8 \mathrm{~h}$ of collection. Plasma samples were frozen at $-20^{\circ} \mathrm{C}$ until assayed. Concentrations of progesterone were evaluated in plasma by RIA using a commercial kit (Coat-a-Count, Siemens Healthcare Diagnostics, Los Angeles, CA). Samples were analyzed in 4 assays with average sensitivity of $0.02 \mathrm{ng} / \mathrm{mL}$, calculated as 2 standard deviations below the mean counts per minute at maximum binding. Plasma harvested from cows on d $4(\sim 1.5 \mathrm{ng} / \mathrm{mL})$ and $10(\sim 5.5 \mathrm{ng} / \mathrm{mL})$ of the estrous cycle was incorporated into each assay and used to calculate the coefficients of variation $(\mathbf{C V})$. The intra- and interassay $\mathrm{CV}$ were 6.0 and $9.0 \%$, respectively.

\section{Pregnancy Diagnosis and Calculation of Reproductive Responses}

Pregnancy was diagnosed by transrectal ultrasonography on d 32 after AI. The presence of an amniotic vesicle containing an embryo with heartbeat was used as the determinant of pregnancy. Pregnant cows on d 32 were re-examined for pregnancy by transrectal palpation on d 60 after AI. Pregnancy per AI was calculated by dividing the number of cows diagnosed pregnant on d 32 or 60 by the number of cows receiving AI. Pregnancy loss was calculated as the number of cows that lost a pregnancy between d 32 and 60 after AI divided by the number of cows diagnosed pregnant on d 32 after AI. Cows detected in estrus before study d 32 were reinseminated and considered as nonpregnant. Short AI interval was defined as cows reinseminated from 5 to 17 after the previous AI.

\section{BCS and Milk Yield}

Body condition was scored in all cows on study d -10 (Ferguson et al., 1994). For statistical analysis, BCS 
was categorized as $\leq 2.50$ or $\geq 2.75$. Yields of milk were recorded for individual cows either daily (herds 1, 2, and 3) or monthly (herds 4 and 5) using on-farm milk meters by the local DHI laboratory. Within herd and parity, cows were divided into quartiles based on milk production in the first 60 DIM.

\section{Experimental Design and Statistical Analyses}

The study was conducted as a randomized complete block design. Within each farm, weekly cohorts of cows without CL were blocked by pen and randomly assigned to remain as nonsupplemented controls or to receive supplemental progesterone during the timed AI program. Cows in diestrus were matched by pen and day of enrollment and used as positive controls to evaluate the efficacy of progesterone supplementation in restoring fertility in cows without CL relative to those with CL. Randomization forms were designed for each pen within farm such that each block contained a representation from each treatment (CON and 2CIDR) in random sequence. Allocation of cows to treatments within block was performed randomly based on sequence of diagnosis of lack of CL. Cows were assigned to DIEST based on sequence of finding as the next cows with a CL following a complete block of cows without CL.

Sample size was calculated using the POWER procedure of SAS (version 9.3; SAS Institute Inc., Cary, NC) based on the main comparison of interest (CON vs. 2CIDR). A total of 623 cows per treatment was deemed necessary to detect a 7.5-percentage-point difference in $\mathrm{P} / \mathrm{AI}$ in response to supplementation with progesterone (30.0 vs. $37.5 \% ; \alpha=0.05 ; \beta=0.20$ ), which is smaller than the expected increase in $\mathrm{P} / \mathrm{AI}$ based on previous studies (Bisinotto et al., 2013).

Binary responses were analyzed by multivariable logistic regression using the GLIMMIX procedure of SAS. Initial models included the fixed effects of herd, parity (primiparous vs. multiparous), BCS category $(\leq 2.50$ vs. $\geq 2.75$ ), milk yield quartile, service number (first AI postpartum vs. resynchronized AI), and the respective interactions with treatment. For the analyses of P/AI and pregnancy loss, sire and AI technician were also included as covariates. Covariates were continuously removed when $P>0.10$ using a backward stepwise elimination method. Treatment was forced into the final model in all analyses. Additional statistical models were built to evaluate whether the effects of treatment on $\mathrm{P} / \mathrm{AI}$ and pregnancy loss were influenced by ovulation in response to the first $\mathrm{GnRH}$ injection of the Ovsynch-56 protocol on study d -10 , presence of CL on study $\mathrm{d}-3$, method of AI (AI on estrus from $\mathrm{d}-9$ to -1 vs. timed AI), or detection of estrus on the day of
AI. The initial models were the same indicated above, but also included each additional covariate (ovulation to $\mathrm{GnRH}$ on $\mathrm{d}-10$, presence of $\mathrm{CL}$ on $\mathrm{d}-3$, method of $\mathrm{AI}$, or detection of estrus at $\mathrm{AI}$ ) and the respective interaction with treatment. Results are presented as adjusted proportions.

In the subset of 2 CIDR cows from which blood was sampled from d -9 to -3 , cows were categorized based on the average concentration of progesterone in $<2.0$ $\mathrm{ng} / \mathrm{mL}(\mathrm{n}=17)$, from 2.0 to $3.0 \mathrm{ng} / \mathrm{mL}(\mathrm{n}=23)$, or $>3.0 \mathrm{ng} / \mathrm{mL}(\mathrm{n}=24)$. Pregnancy per AI on d 32 was analyzed by univariable logistic regression using the GLIMMIX procedure of SAS. The statistical model included the fixed effect of progesterone category. Orthogonal contrasts were built to compare $\mathrm{P} / \mathrm{AI}$ in cows with average progesterone concentrations $<2.0 \mathrm{ng} / \mathrm{mL}$ with those with $\geq 2.0 \mathrm{ng} / \mathrm{mL}$ and cows with 2.0 to 3.0 $\mathrm{ng} / \mathrm{mL}$ versus those with $>3.0 \mathrm{ng} / \mathrm{mL}$.

Continuous and discrete variables were analyzed by ANOVA using the GLIMMIX procedure of SAS fitting a normal distribution. Tests for normality of residuals and homogeneity of variances were conducted for each dependent variable. The fixed effects of treatment, parity, service number, and the respective interactions with treatment were included in the models as independent variables. Concentrations of progesterone were analyzed as repeated measures and cow was considered a random effect. Cows that underwent luteolysis before study d 13 were removed from the analysis of progesterone concentrations after AI. The covariance structure with the smallest Schwarz's Bayesian information criterion value was selected for each analysis. Results are presented as least squares means and standard errors of the mean $(\mathrm{LSM} \pm \mathrm{SEM})$.

Differences with $P \leq 0.05$ were considered significant and those with $0.05<P \leq 0.10$ were considered tendencies. Whenever a treatment effect was detected $(P$ $<0.10$ ), pairwise comparisons were performed using the method of Tukey.

\section{RESULTS}

The prevalence of cows without CL at initiation of the Ovsynch-56 protocol was $27.0 \%$, with individual herd prevalences of 23.0, 27.2, 32.6, 22.1, and $38.5 \%$ in dairies $1,2,3,4$, and 5 , respectively. Of the initial 642 cows assigned to receive supplemental progesterone, none lost one insert and $7(1.1 \%)$ lost both inserts before removal on $\mathrm{d}-3$. These 7 cows were excluded from all statistical analyses. In addition, 5 cows left the study before pregnancy diagnosis on d $32(\mathrm{CON}=3$; $2 \mathrm{CIDR}=2$ ), and 17 cows left the study before pregnancy diagnosis on d 60 after $\mathrm{AI}(\mathrm{CON}=7 ; 2 \mathrm{CIDR}$ 
$=3 ;$ DIEST $=7)$. Body condition at enrollment and the proportion of cows classified as having BCS $\geq 2.75$ did not differ among treatments and averaged 2.86 and $79.0 \%$, respectively. Milk yield during the first 60 DIM averaged $36.8 \mathrm{~kg} / \mathrm{d}$ and did not differ among treatments.

\section{Ovarian Responses to the Timed Al Protocol}

The proportions of cows that ovulated in response to the first GnRH and that had a new CL present at the $\mathrm{PGF}_{2 \alpha}$ injection were greater $(P<0.001)$ for $\mathrm{CON}$ and 2CIDR compared with DIEST (Table 1). However, progesterone supplementation did not affect the ovulatory response to the initial GnRH or the proportion of cows with a new CL on $\mathrm{d}-3$. Ovulation in response to the first $\mathrm{GnRH}$ was greater $(P<0.001)$ among cows receiving the first $\mathrm{AI}$ postpartum compared with those receiving resynchronized AI (62.9 vs. 51.6\%). Nevertheless, no interaction between treatment and service number was observed. In spite of a smaller ovulatory response to the initial $\mathrm{GnRH}$, the proportion of cows with CL at the $\mathrm{PGF}_{2 \alpha}$ injection was greater $(P<0.001)$ for cows in DIEST compared with CON and 2CIDR cows. A greater $(P<0.01)$ proportion of cows receiving the first AI postpartum had a CL present on $\mathrm{d}$ -3 compared with those subjected to resynchronized AI ( 80.1 vs. $73.6 \%$ ). No interaction between treatment and service number was observed. The diameter of the ovulatory follicle and the proportion of cows that ovulated in response to the second $\mathrm{GnRH}$ injection did not differ among treatments (Table 1). The aforementioned responses were not affected by interactions between treatment and parity, AI number, and milk yield.

\section{Concentrations of Progesterone Before and After AI}

Concentrations of progesterone in plasma on study $\mathrm{d}-10$ were greater $(P<0.001)$ for cows in DIEST compared with CON and 2CIDR cows (Figure 2). The incorporation of 2 intravaginal inserts to the Ovsynch-56 protocol increased $(P<0.001)$ concentrations of progesterone from $\mathrm{d}-9$ to -3 in cows without a CL, but they remained lower $(P<0.001)$ than those observed in DIEST cows. A treatment by day interaction $(P<0.01)$ was observed because concentrations of progesterone in CON and DIEST cows increased from $\mathrm{d}-9$ to -3 , whereas no change was observed in 2CIDR cows. The interaction between treatment and parity affected $(P=0.01)$ progesterone concentrations between $\mathrm{d}-9$ and -3 because for 2CIDR (primiparous $=3.60$ and multiparous $=2.33 \mathrm{ng} / \mathrm{mL}$ ) and DIEST $($ primiparous $=5.98$ and multiparous $=4.68 \mathrm{ng} / \mathrm{mL}$ ) primiparous had greater concentrations of progesterone than multiparous, but the same was not observed in $\mathrm{CON}$ (primiparous $=0.72$ and multiparous $=0.98$ $\mathrm{ng} / \mathrm{mL}$ ). Progesterone concentrations from $\mathrm{d}-9$ to -3 were also affected $(P=0.01)$ by the interaction between treatment and AI number because concentrations were numerically smaller in CON and DIEST at first compared with resynchronized AI (CON, 0.81 and $0.89 \mathrm{ng} / \mathrm{mL}$; DIEST, 4.80 and $5.85 \mathrm{ng} / \mathrm{mL})$, but the opposite was observed in 2CIDR (3.37 and $2.55 \mathrm{ng} /$ $\mathrm{mL}$ ). Concentrations of progesterone on $\mathrm{d} 0$ did not

Table 1. Effect of the presence of corpus luteum (CL) and progesterone supplementation for cows without CL at the initiation of the Ovsynch protocol on ovarian responses and synchrony of the estrous cycle

\begin{tabular}{|c|c|c|c|c|}
\hline \multirow[b]{2}{*}{ Item } & \multicolumn{3}{|c|}{ Treatment $^{1}$} & \multirow[b]{2}{*}{$P$-value } \\
\hline & $\mathrm{CON}$ & 2CIDR & DIEST & \\
\hline \multicolumn{5}{|l|}{ Ovulation to the first $\mathrm{GnRH},{ }^{2} \%$ (no.) } \\
\hline All cows & $63.6(523)^{\mathrm{a}}$ & $61.1(532)^{\mathrm{a}}$ & $47.2(503)^{\mathrm{b}}$ & $<0.001$ \\
\hline Cows with follicles $\geq 10 \mathrm{~mm}$ & $67.0(493)^{\mathrm{a}}$ & $63.9(506)^{\mathrm{a}}$ & $47.7(494)^{b}$ & $<0.001$ \\
\hline Cows with new CL at $\mathrm{PGF}_{2 \alpha},{ }^{3} \%$ (no.) & $72.4(523)^{\mathrm{a}}$ & $67.9(532)^{\mathrm{a}}$ & $47.4(503)^{\mathrm{b}}$ & $<0.001$ \\
\hline Cows with CL at $\mathrm{PGF}_{2 \alpha}, \%$ (no.) & $71.0(523)^{\mathrm{b}}$ & $66.5(532)^{\mathrm{b}}$ & $88.5(503)^{\mathrm{a}}$ & $<0.001$ \\
\hline Ovulation to the second $\mathrm{GnRH},{ }^{4} \%$ (no.) & $83.6(67)$ & $83.6(67)$ & $90.5(63)$ & 0.44 \\
\hline \multicolumn{5}{|l|}{ Ovulatory follicle ${ }^{5} \mathrm{~mm}$ (LSM $\left.\pm \mathrm{SEM}\right)$} \\
\hline All cows & $17.5 \pm 0.4$ & $16.8 \pm 0.4$ & $17.7 \pm 0.4$ & 0.22 \\
\hline Cows with new $\mathrm{CL}$ at $\mathrm{PGF}_{2 \alpha}$ & $17.3 \pm 0.4$ & $16.5 \pm 0.4$ & $17.5 \pm 0.4$ & 0.17 \\
\hline
\end{tabular}

${ }_{\mathrm{a}, \mathrm{b}}$ Values within a row different superscripts differed $(P \leq 0.05)$.

${ }^{1}$ All cows were subjected to the Ovsynch-56 protocol ( $\mathrm{d}-10 \mathrm{GnRH}, \mathrm{d}-3 \mathrm{PGF}_{2 \alpha}, \mathrm{d}-0.7 \mathrm{GnRH}, \mathrm{d} 0$ timed $\mathrm{AI}) . \mathrm{CON}=$ cows without a $\mathrm{CL}$ on $\mathrm{d}-10$ (control); $2 \mathrm{CIDR}=$ cows without a CL on $\mathrm{d}-10$ treated with 2 controlled internal drug-release inserts containing $1.38 \mathrm{~g}$ of progesterone each from $\mathrm{d}-10$ to -3 ; DIEST $=$ cows with CL on $\mathrm{d}-10$.

${ }^{2}$ Follicle $\geq 10 \mathrm{~mm}$ present on $\mathrm{d}-10$ and appearance of a new CL in the same ovary on $\mathrm{d}-3$.

${ }^{3}$ New CL detected on $\mathrm{d}-3$ that was not present on $\mathrm{d}-10$.

${ }^{4}$ Follicle $\geq 10 \mathrm{~mm}$ present on $\mathrm{d}-0.7$ that disappeared within $40 \mathrm{~h}$ of the second GnRH injection.

${ }^{5}$ Only cows that ovulated in response to the second $\mathrm{GnRH}$ were included in the analysis. 


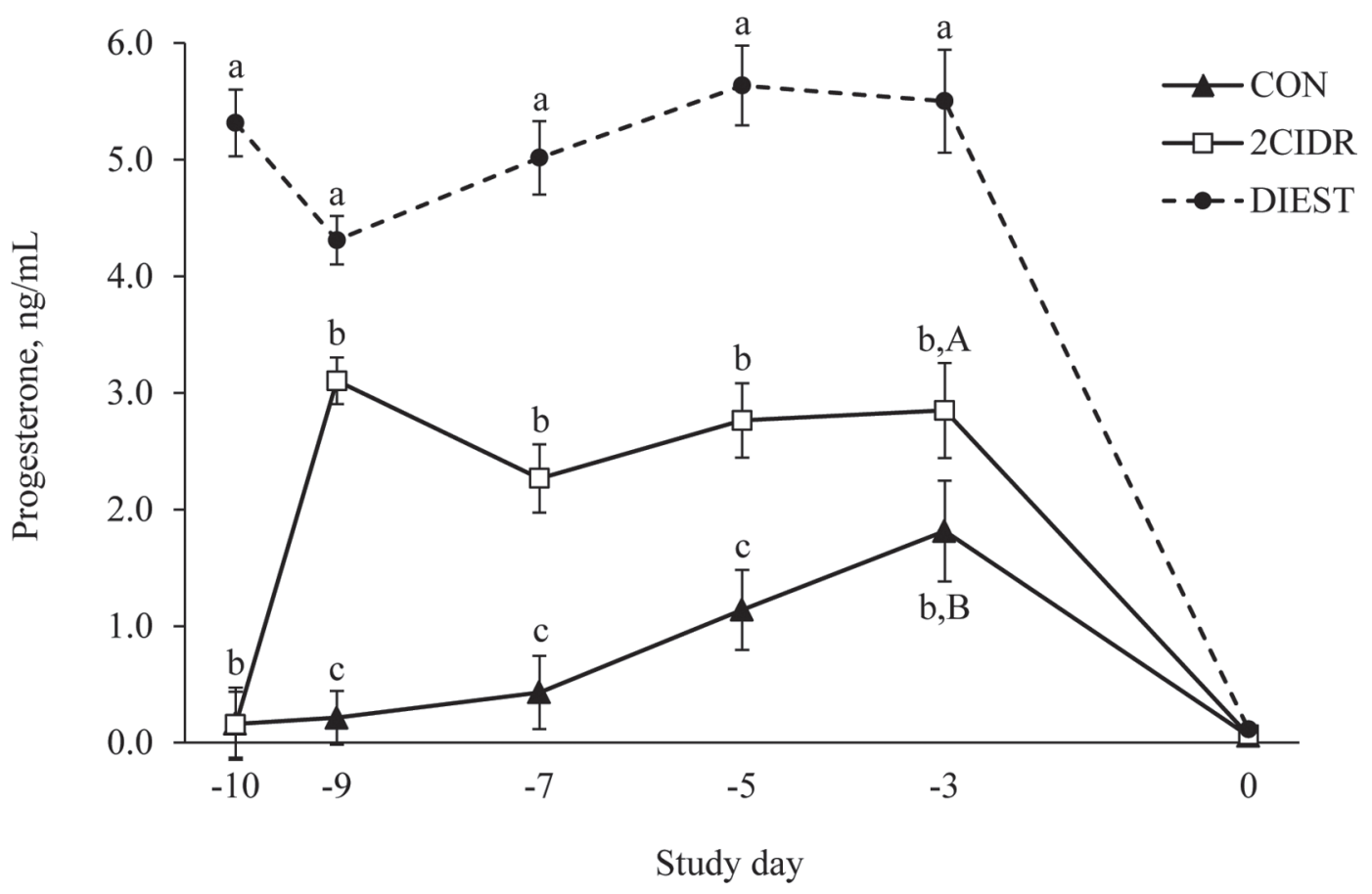

Figure 2. Concentrations of progesterone in plasma during the synchronization protocol. Cows were subjected to the Ovsynch-56 protocol (d -10 GnRH, d $-3 \mathrm{PGF}_{2 \alpha}, \mathrm{d}-0.7 \mathrm{GnRH}, \mathrm{d} 0$ timed AI). CON $=$ cows without $\mathrm{CL}$ on $\mathrm{d}-10(\mathrm{n}=37$; control); $2 \mathrm{CIDR}=$ cows without $\mathrm{CL}$ on $\mathrm{d}-10$ and treated with 2 controlled internal drug-release inserts containing $1.38 \mathrm{~g}$ of progesterone each from $\mathrm{d}-10$ to -3 ( $\mathrm{n}=38) ;$ DIEST $=$ cows with CL on $\mathrm{d}-10(\mathrm{n}=34)$. Progesterone concentrations from $\mathrm{d}-9$ to -3 averaged $0.92 \pm 0.27,2.77 \pm 0.25$, and $4.93 \pm 0.26 \mathrm{ng} / \mathrm{mL}$ for CON, 2CIDR, and DIEST treatments, respectively. Effects of treatment $(P<0.001)$, day $(P<0.01)$, and interaction between treatment and day $(P<0.01)$. Within day, concentrations of progesterone differed $\left({ }^{\mathrm{a}-\mathrm{c}} P \leq 0.05\right)$ or tended to differ $\left({ }^{\mathrm{A}, \mathrm{B}} 0.05<P \leq 0.10\right)$ among treatments.

differ among treatments or interactions between treatment and parity or AI number, and averaged $0.08 \pm$ $0.03 \mathrm{ng} / \mathrm{mL}$. After AI, treatment, parity, AI number, or interactions between treatment and covariates did not affect concentrations of progesterone (Figure 3).

\section{Expression of Estrus at AI}

The proportion of cows inseminated in estrus before timed AI did not differ among treatments (Table 2), although an interaction $(P=0.03)$ between treatment and service number was observed. For cows receiving the first AI postpartum, the proportion inseminated from $\mathrm{d}-9$ to -1 was greater $(P \leq 0.05)$ for $\mathrm{CON}$ and DIEST compared with 2 CIDR $(\mathrm{CON}=15.7$ vs. $2 \mathrm{CIDR}$ $=9.6$ vs. DIEST $=15.8 \%$ ). On the other hand, treatment did not affect insemination on estrus for cows receiving resynchronized $\mathrm{AI}(\mathrm{CON}=16.5$ vs. $2 \mathrm{CIDR}$ $=18.6$ vs. DIEST $=16.3 \%)$. No interactions were detected between treatment and parity or milk yield. The timing at which cows were inseminated before timed AI was also influenced by treatment (Table 2). A larger proportion of CON and DIEST cows were inseminated before the $\mathrm{PGF}_{2 \alpha}$ injection compared with $2 \mathrm{CIDR}$. The interactions between treatment and parity, AI number, and milk yield did not affect the proportion of cows inseminated in estrus from $\mathrm{d}-9$ to -3 . Conversely, a greater proportion of 2 CIDR cows were inseminated in estrus between the day of $\mathrm{PGF}_{2 \alpha}$ injection and that of timed AI.

The proportion of cows in estrus on the day of AI, which includes cows inseminated in estrus before d 0 and those in estrus at timed AI, was greater $(P<0.05)$ for CON and 2CIDR compared with DIEST (Table 2). Interactions between treatment and parity, AI number, and milk yield did not affect the proportion of cows in estrus at AI.

\section{Pregnancy per Al and Pregnancy Loss}

Pregnancy per AI on d 32 and 60 after insemination was greater $(P<0.05)$ for 2 CIDR than for CON cows (Table 2). In fact, 2CIDR cows had P/AI similar to that of DIEST cows. Cows receiving the first AI postpartum had greater $(P=0.04) \mathrm{P} / \mathrm{AI}$ on d $32(39.8$ vs. $34.6 \%)$ but not on d 60 after AI (33.8 vs. 32.6\%) compared with cows receiving a resynchronized insemination. The interaction between treatment and service number did 
Table 2. Effect of the presence of corpus luteum (CL) and progesterone supplementation for cows without CL at the initiation of the Ovsynch protocol on fertility responses

\begin{tabular}{|c|c|c|c|c|}
\hline \multirow[b]{2}{*}{ Item, \% (no.) } & \multicolumn{3}{|c|}{ Treatment $^{1}$} & \multirow[b]{2}{*}{$P$-value } \\
\hline & $\mathrm{CON}$ & 2CIDR & DIEST & \\
\hline Estrus at $\mathrm{AI}^{2}$ & $35.8(652)^{\mathrm{a}}$ & $39.6(635)^{\mathrm{a}}$ & $30.6(640)^{\mathrm{b}}$ & $<0.01$ \\
\hline Inseminated before timed AI & $16.2(652)$ & $16.0(635)$ & $13.5(640)$ & 0.33 \\
\hline From d -9 to -3 & $5.7(652)^{\mathrm{b}}$ & $0.0(635)^{\mathrm{c}}$ & $9.4(640)^{\mathrm{a}}$ & $<0.001$ \\
\hline From $\mathrm{d}-2$ to -1 & $11.8(652)^{\mathrm{B}}$ & $15.1(635)^{\mathrm{a}, \mathrm{A}}$ & $8.0(640)^{\mathrm{b}, \mathrm{C}}$ & $<0.001$ \\
\hline Short reinsemination interval ${ }^{3}$ & $20.6(224)$ & $15.1(196)$ & $14.1(239)$ & 0.12 \\
\hline \multicolumn{5}{|l|}{ Pregnant } \\
\hline d 32 & $31.3(649)^{\mathrm{b}}$ & $42.2(633)^{\mathrm{a}}$ & $38.4(640)^{\mathrm{a}}$ & 0.001 \\
\hline d 60 & $28.9(642)^{\mathrm{b}, \mathrm{B}}$ & $37.2(630)^{\mathrm{a}}$ & $33.9(633)^{\mathrm{A}}$ & 0.01 \\
\hline Pregnancy loss & $8.5(208)$ & $11.4(260)$ & $8.8(231)$ & 0.48 \\
\hline
\end{tabular}

${ }^{\mathrm{a}-\mathrm{c}}$ Values within a row with different superscripts differed $(P \leq 0.05)$.

${ }^{\mathrm{A}-\mathrm{C}}$ Values within a row with different superscripts tended to differ $(0.05<P \leq 0.10)$.

${ }^{1}$ All cows were subjected to the Ovsynch-56 protocol (d -10 GnRH, d $-3 \mathrm{PGF}_{2 \alpha}, \mathrm{d}-0.7 \mathrm{GnRH}, \mathrm{d} 0$ timed $\mathrm{AI}) . \mathrm{CON}=$ cows without a $\mathrm{CL}$ on $\mathrm{d}-10$ (control); $2 \mathrm{CIDR}=$ cows without a CL on $\mathrm{d}-10$ treated with 2 controlled internal drug-release inserts containing $1.38 \mathrm{~g}$ of progesterone each from $\mathrm{d}-10$ to -3 ; DIEST $=$ cows with CL on $\mathrm{d}-10$.

${ }^{2}$ Includes cows inseminated in estrus before timed AI and those in estrus at timed AI.

${ }^{3}$ Nonpregnant cows on d 32 after AI reinseminated from 5 to $17 \mathrm{~d}$ after previous AI. Includes only reinseminated cows before pregnancy diagnosis on $\mathrm{d} 32$.

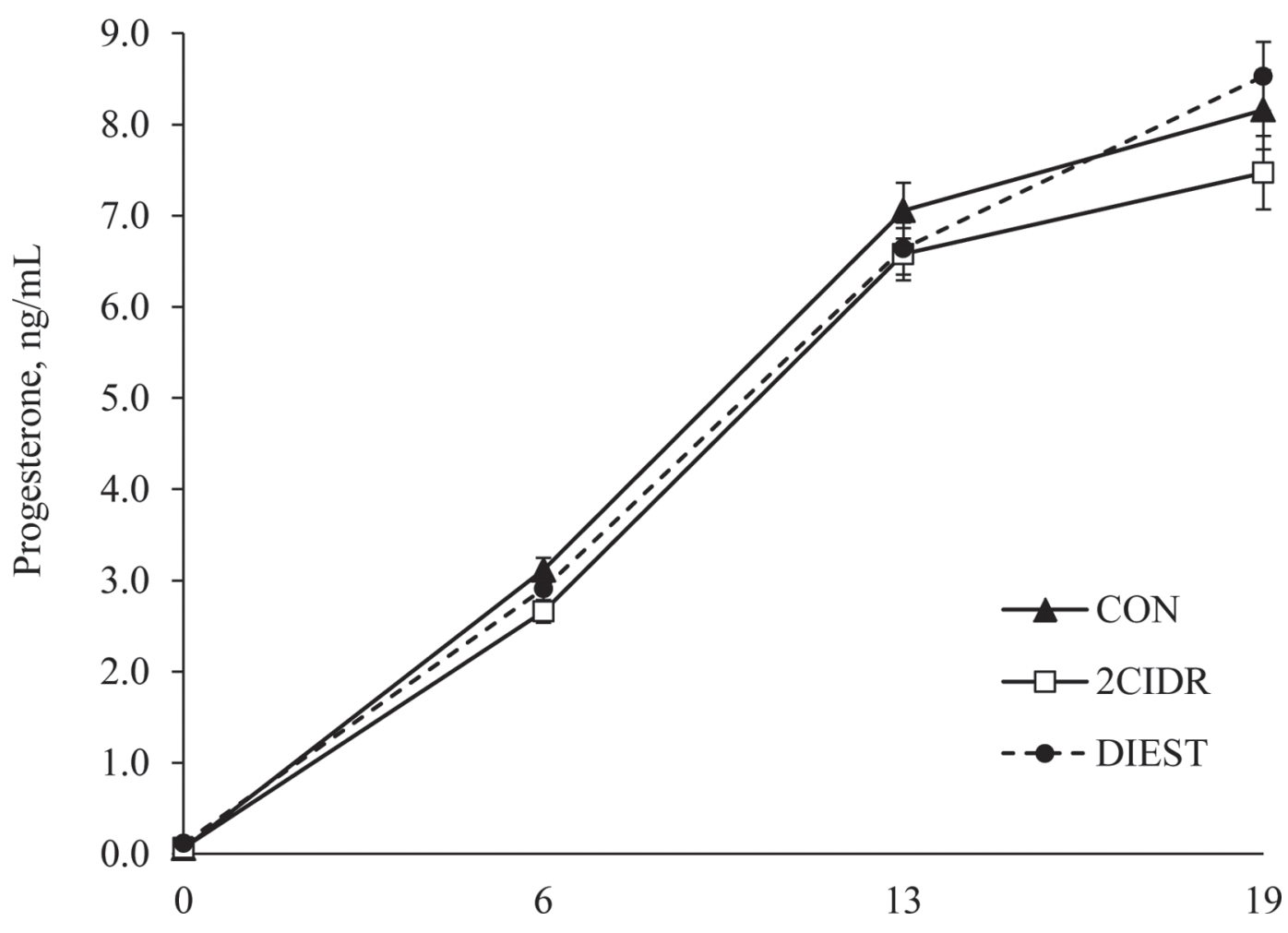

Study day

Figure 3. Concentrations of progesterone in plasma during the first $19 \mathrm{~d}$ after AI. Cows were subjected to the Ovsynch-56 protocol (d -10 GnRH, d $-3 \mathrm{PGF}_{2 \alpha}, \mathrm{d}-0.7 \mathrm{GnRH}$, d 0 timed $\left.\mathrm{AI}\right)$. CON $=$ cows without $\mathrm{CL}$ on $\mathrm{d}-10$ ( $\mathrm{n}=49$; control); 2CIDR $=$ cows without CL on $\mathrm{d}-10$ and treated with 2 controlled internal drug-release inserts containing $1.38 \mathrm{~g}$ of progesterone each from d -10 to $-3(\mathrm{n}=54)$; DIEST $=$ cows with CL on d $-10(\mathrm{n}=53)$. Progesterone concentrations from d 6 to 19 averaged $6.11 \pm 0.22,5.57 \pm 0.20$, and $6.03 \pm 0.20 \mathrm{ng} / \mathrm{mL}$ for CON, $2 \mathrm{CIDR}$, and DIEST treatments, respectively. Effects of treatment $(P=0.15)$, day $(P<0.001)$, and interaction between treatment and day $(P=0.47)$. 
not affect $\mathrm{P} / \mathrm{AI}$ on $\mathrm{d} 32$ or 60 . The increase in $\mathrm{P} / \mathrm{AI}$ in response to progesterone supplementation observed on d 60 after insemination was similar for cows receiving the first $(\mathrm{CON}=29.8$ vs. $2 \mathrm{CIDR}=35.2 \%)$ and the resynchronized $\mathrm{AI}(\mathrm{CON}=29.0$ vs. $2 \mathrm{CIDR}=37.7 \%)$. Similarly, the interaction between treatment and covariates did not affect $\mathrm{P} / \mathrm{AI}$.

Cows detected in estrus on the day of AI, which includes those inseminated before and those in estrus at timed AI, had greater P/AI on d 32 and 60 after insemination than cows not detected in estrus (Table 3 ). An interaction between treatment and detection of estrus was observed to affect $\mathrm{P} / \mathrm{AI}$ (Table 3 ). Treatment did not influence $\mathrm{P} / \mathrm{AI}$ in cows detected in estrus, whereas for those not in estrus, cows in 2CIDR and DIEST had greater $\mathrm{P} / \mathrm{AI}$ than cows in CON. Detection of a new CL on the day of $\mathrm{PGF}_{2 \alpha}$ injection increased $\mathrm{P} / \mathrm{AI}$ (Table 4 ), and the benefits of developing the preovulatory follicle under high progesterone with 2CIDR and DIEST on $\mathrm{P} / \mathrm{AI}$ were only observed in cows without a new CL.

The proportion of nonpregnant cows reinseminated from 5 to $17 \mathrm{~d}$ after AI did not differ among treatments (Table 2). The interactions between treatment and parity, AI number, and milk yield did not affect the proportion of cows reinseminated from 5 to $17 \mathrm{~d}$ after AI. Cows detected in estrus on the day of AI were less likely $(P=0.01)$ to be reinseminated from $\mathrm{d} 5$ to 17 compared with those that did not display signs of estrus (19.0 vs. 11.6\%). The proportion of cows reinseminated from d 5 to 17 after AI did not differ with the presence of a new CL at the $\mathrm{PGF}_{2 \alpha}$ injection on $\mathrm{d}-3$.

Pregnancy loss between d 32 and 60 of gestation did not differ among treatments (Table 2). Service number, detection of estrus (Table 3), presence of a new CL at $\mathrm{PGF}_{2 \alpha}$ (Table 4), or the respective interactions with treatment did not affect pregnancy loss. The interactions between treatment and parity, AI number, and milk yield did not affect the proportion of cows that lost a pregnancy between d 32 and 60 of gestation.

\section{Pregnancy per Al in 2CIDR Cows Based on Progesterone Concentrations}

The mean concentration of progesterone in 2CIDR cows from d -9 to -3 ranged between 0.7 and $7.0 \mathrm{ng} /$ $\mathrm{mL}$. Cows were classified as having $<2.0 \mathrm{ng} / \mathrm{mL}(1.7 \pm$ 0.3 ; range: 0.7 to 1.98$), 2.0$ to $3.0 \mathrm{ng} / \mathrm{mL}(2.5 \pm 0.3$; range: 2.1 to 3.0$)$, or $>3.0 \mathrm{ng} / \mathrm{mL}(4.0 \pm 0.9$; range 3.1 to 7.0$)$. Pregnancy on d 32 after AI tended to be greater $(P=0.08)$ for cows with concentrations of progesterone above $2.0 \mathrm{ng} / \mathrm{mL}$, whereas no difference was observed between cows with concentrations between 2.0 and $3.0 \mathrm{ng} / \mathrm{mL}$ and those with more than $3.0 \mathrm{ng} / \mathrm{mL}$ (Figure 4).

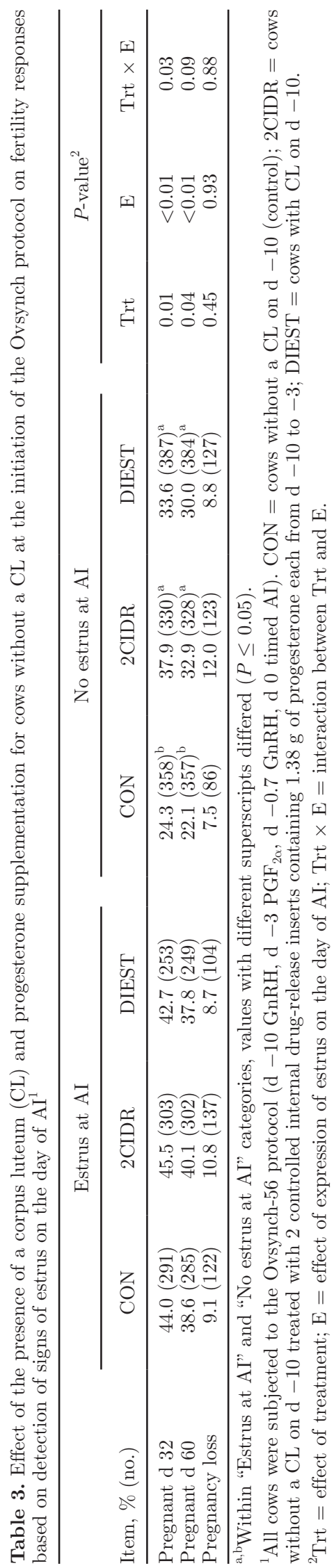

Journal of Dairy Science Vol. 98 No. 4, 2015 


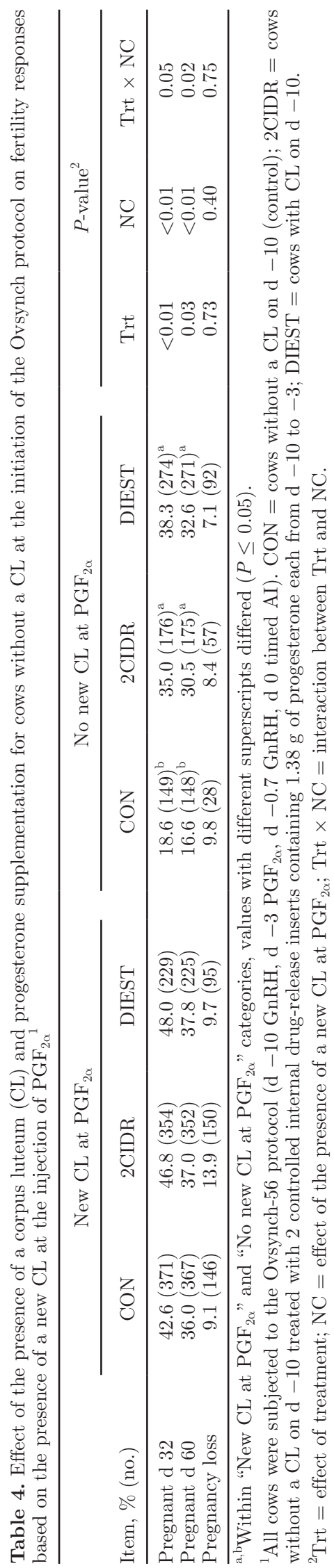

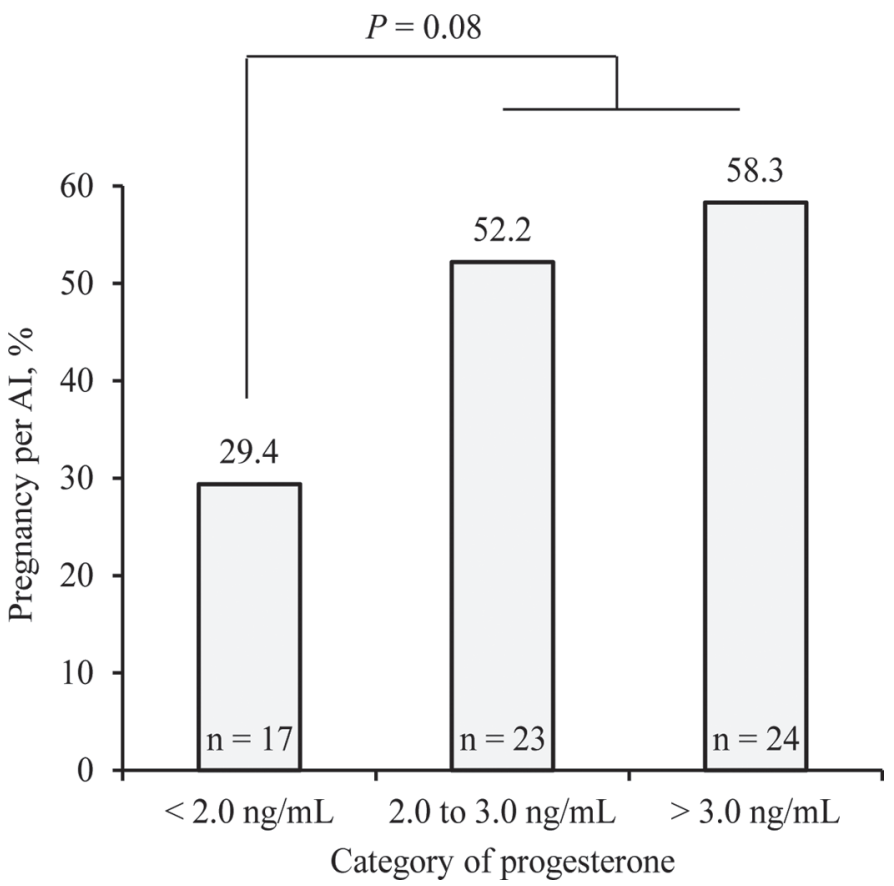

Figure 4. Pregnancy per AI on d 32 after insemination in 2CIDR cows based on the concentrations of progesterone during follicle growth. Cows without CL were subjected to the Ovsynch-56 protocol (d $-10 \mathrm{GnRH}, \mathrm{d}-3 \mathrm{PGF}_{2 \alpha}, \mathrm{d}-0.7 \mathrm{GnRH}, \mathrm{d} 0$ timed $\mathrm{AI}$ ) and received 2 controlled internal drug-release inserts containing $1.38 \mathrm{~g}$ of progesterone each from $\mathrm{d}-10$ to -3 . Cows were categorized based on the average concentration of progesterone from $\mathrm{d}-9$ to -3 as having $<2.0$ $\mathrm{ng} / \mathrm{mL}(1.66 \pm 0.32 \mathrm{ng} / \mathrm{mL})$, from 2.0 to $3.0 \mathrm{ng} / \mathrm{mL}(2.53 \pm 0.26 \mathrm{ng} /$ $\mathrm{mL})$, or $>3.0 \mathrm{ng} / \mathrm{mL}(3.97 \pm 0.89 \mathrm{ng} / \mathrm{mL})$.

\section{DISCUSSION}

According to the initial hypotheses, supplementing progesterone with 2 intravaginal inserts increased concentrations of progesterone during the growth of the ovulatory follicle by $1.85 \mathrm{ng} / \mathrm{mL}$ and restored $\mathrm{P} / \mathrm{AI}$ in lactating dairy cows without CL at the initiation of the Ovsynch protocol comparable to that of cows in diestrus. The benefit of exogenous progesterone to fertility of cows lacking a CL was similar between those receiving the first or resynchronized AI. Estrous cyclicity was not evaluated in the present study, but approximately $70 \%$ of the cows that do not have a CL from 12 to 14 $\mathrm{d}$ after receiving $\mathrm{PGF}_{2 \alpha}$ are expected to be anovular (Bisinotto et al., 2010). Thus, the improvement in P/AI observed for 2CIDR in the present study was likely observed in anovular cows as well as in estrous cyclic cows not in diestrus when the Ovsynch was initiated. These results are in agreement with previous studies in which increasing the concentrations of progesterone above 2.5 $\mathrm{ng} / \mathrm{mL}$ throughout the timed AI protocol restored $\mathrm{P} /$ AI in cows without a CL similar to that of cows in diestrus (Bisinotto et al., 2013). These results provide 
further evidence that progesterone is a key regulator of fertility during development of the ovulatory follicle (Bisinotto et al., 2010; Wiltbank et al., 2011).

The importance of progesterone during final development of the preovulatory follicle has been demonstrated via several experimental designs. Early studies showed that cows with high concentrations of progesterone before insemination had greater $\mathrm{P} / \mathrm{AI}$ compared with herdmates with low concentrations (Folman et al., 1973; Fonseca et al., 1983). Cows inseminated in estrus after an injection of $\mathrm{PGF}_{2 \alpha}$ from $\mathrm{d} 5$ to 9 of the estrous cycle had smaller $\mathrm{P} / \mathrm{AI}$ than those treated with $\mathrm{PGF}_{2 \alpha}$ administered from d 10 to 19 (Xu et al., 1997). More importantly, supplementation with progesterone preceding the injection of $\mathrm{PGF}_{2 \alpha}$ blunted the effect of stage of estrous cycle on $\mathrm{P} / \mathrm{AI}$, indicating that the changes in fertility were mediated, in part, by differences in progesterone concentrations during follicle growth $(\mathrm{Xu}$ et al., 1997). A decrease in $\mathrm{P} / \mathrm{AI}$ has been observed in cows enrolled in synchronization protocols while anovular or during the follicular phase of the estrous cycle compared with cows in diestrus (Bisinotto et al., 2010; Wiltbank et al., 2011; Denicol et al., 2012).

Supplementing progesterone to cows without a CL, although intuitive, relies on systems for sustained delivery of sufficient amounts to mimic concentrations of observed in cows in diestrus. Commercially available devices such as the CIDR were originally designed for grazing heifers (Macmillan et al., 1991), and their use resulted in concentrations of progesterone in high-producing Holstein cows well below those observed during diestrus (Sartori et al., 2004; Cerri et al., 2009a). The CIDR insert releases approximately 89 mg of progesterone daily (Rathbone et al., 2002), which increases concentrations in plasma of heifers to 5 to 8 $\mathrm{ng} / \mathrm{mL}$ (Macmillan et al., 1991), but only to $0.8 \mathrm{ng} /$ $\mathrm{mL}$ in lactating dairy cows (Cerri et al., 2009a). The low concentrations observed in lactating cows are due to the extensive steroid catabolism by the splanchnic tissues (Wiltbank et al., 2011). The marginal increase in circulating progesterone observed with a single insert improves P/AI in anovular cows or those without a CL (Bisinotto et al., 2015); however, it results in fertility that is less than that observed in cows subjected to timed AI during diestrus (Stevenson et al., 2008; Lima et al., 2009; Bisinotto and Santos, 2011).

Results from the current experiment suggest that a minimum concentration of progesterone of approximately $2.0 \mathrm{ng} / \mathrm{mL}$ is needed to sustain high fertility in lactating dairy cows. Although incorporating 2 CIDR inserts in the Ovsynch protocol improved $\mathrm{P} / \mathrm{AI}$ in cows without a CL, analysis of the subset of cows with blood sampling indicated that the benefits were observed when concentrations of progesterone increased above $2.0 \mathrm{ng} /$
$\mathrm{mL}$. Although excessive concentrations of progesterone can induce atresia and turnover of the dominant follicle (Anderson and Day, 1994), a reduction in P/AI was not observed when progesterone concentrations increased up to $7.0 \mathrm{ng} / \mathrm{mL}$. Collectively, the current findings and those of others (Denicol et al., 2012; Bisinotto et al., 2013) support the concept that a minimum concentration of progesterone during the growth of the preovulatory follicle is needed to optimize fertility in dairy cows and that 2- to 3-fold the amount of progesterone released by a single CIDR is needed to achieve such a concentration in high-producing Holstein cows without a CL.

The mechanisms that underlie the reduction in $\mathrm{P} /$ AI observed in anovular cows and those with low progesterone concentrations during development of the ovulatory follicle likely involve changes in LH release. Decreasing circulating progesterone increases basal LH concentrations, which in turn hasten follicle growth, increase the diameter of the ovulatory follicle, and reduce follicular fluid IGF-1 concentration (Cerri et al., 2011). An increase in LH concentrations has also been associated with advanced oocyte maturation, characterized by premature resumption of meiosis and breakdown of the germinal vesicle (Revah and Butler, 1996). Lactating dairy cows superstimulated with FSH in the absence of a functional CL had reduced embryo quality on d 7 after AI compared with cows initiating the FSH treatment in diestrus (Rivera et al., 2011). Interestingly, using 2 CIDR inserts during follicle growth increased circulating concentrations of progesterone to about $3.0 \mathrm{ng} / \mathrm{mL}$ and restored embryo quality in cows without CL. Collectively, these data indicate that the suboptimal progesterone concentrations during final stages of follicle development alter the biochemical composition of the follicular fluid, compromise oocyte quality, and reduce subsequent embryo viability, all of which are likely to depress $\mathrm{P} / \mathrm{AI}$ in dairy cows.

Despite increasing the average concentration of progesterone from 0.92 to $2.77 \mathrm{ng} / \mathrm{mL}$ between $\mathrm{d}-9$ and -3 , the use of 2 intravaginal inserts did not affect the diameter of the ovulatory follicle in cows without CL in the present study. Previously, supplementing progesterone with 2 CIDR to cows without CL in the 5-d timed AI protocol reduced the rate of follicle growth and resulted in smaller ovulatory follicles compared with untreated controls (Bisinotto et al., 2013). It is possible that the additional days between the first $\mathrm{GnRH}$ and the injection of $\mathrm{PGF}_{2 \alpha}$ allowed for follicles in 2CIDR and DIEST cows to continue growing, whereas follicles in CON cows had reached the static phase. Nevertheless, it is reasonable to speculate that the changes in $\mathrm{P} /$ AI observed in the present study were associated with changes in the intrafollicular environment and oocyte 
competence even though treatment did not affect the diameter of the ovulatory follicle. In fact, supplementing progesterone with 2 intravaginal inserts to cows lacking a CL does not consistently reduce the preovulatory follicle diameter in the timed AI protocols with 7 $\mathrm{d}$ between the first $\mathrm{GnRH}$ and the injection of $\mathrm{PGF}_{2 \alpha}$ (Lima et al., 2009; Denicol et al., 2012).

It is interesting to note that the benefit of supplemental progesterone to cows without a CL was observed only in those that did not display signs of estrus at AI. Cows in CON that showed estrus at AI had similar P/ AI to those in 2CIDR and DIEST. This interaction between expression of estrus at $\mathrm{AI}$ and concentrations of progesterone during follicular growth was also observed in cows without CL subjected to the 5-d timed AI program (Bisinotto et al., 2013). It seems that cows that are capable of expressing estrus at AI do not suffer from reduced fertility when the follicle develops under low progesterone. Perhaps expression of estrus is a sign of proper maturation of the ovulatory follicle that ultimately culminates in ovulation of a competent oocyte upon estrus. Nevertheless, expression of estrus in cows without a CL in timed AI protocols is rather low, approximately 35\% (Bisinotto et al., 2013), which emphasizes the need to optimize fertility in these cows with supplemental progesterone.

A legacy effect of preovulatory concentrations of progesterone on uterine function cannot be discounted. Cows with reduced concentrations of progesterone during the growth of the ovulatory follicle have greater $\mathrm{PGF}_{2 \alpha}$ synthesis in response to oxytocin in the subsequent diestrus (Shaham-Albalancy et al., 2001; Cerri et al., 2011), which might impair the capacity of the conceptus to block the luteolytic cascade and maintain pregnancy. Previous studies have shown that supplementing progesterone to dairy cows lacking a CL when the timed AI program was initiated reduced the proportion of cows with short estrous cycles after AI (Bisinotto et al., 2013). The proportion of cows reinseminated from 5 to $17 \mathrm{~d}$ after AI was numerically smaller for 2CIDR compared with CON and DIEST in the present study, suggesting that a similar mechanism might have accounted for some of the differences in P/AI among treatments. Furthermore, results from Shaham-Albalancy et al. (1997) indicate that the use of intravaginal inserts containing progesterone during development of the ovulatory follicle altered the morphology of endometrial glands and the uterine vasculature in the subsequent diestrus. It is possible that these changes in uterine morphology lead to differences in histotroph production and intrauterine environment during early embryo development. Nevertheless, further evaluation of this hypothesis is necessary.
The decrease in $\mathrm{P} / \mathrm{AI}$ in $\mathrm{CON}$ cows was not associated with reduced synchrony of the estrous cycle in response to the timed AI protocol. In fact, the proportion of cows that ovulated following the initial GnRH and that had a new CL present on $\mathrm{d}-3$ was greater for cows without CL at the initiation of the Ovsynch protocol than for cows in diestrus in the present study. The current results are in agreement with previous studies that observed better synchrony of follicular growth in anovular (Gümen et al., 2003) and cyclic cows in proestrus (Bisinotto et al., 2010) compared with cows in diestrus. Dairy cows that fail to ovulate in response to the initial GnRH have an extended period of follicle dominance, which impairs early embryo quality and compromises fertility (Bleach et al., 2004; Cerri et al., 2009b). The detrimental effects of lengthening follicular dominance are expected to be intensified in cows with low concentrations of progesterone because of greater exposure to LH. In fact, the decrease in $\mathrm{P} / \mathrm{AI}$ in cows without CL on $\mathrm{d}-10$ was observed mostly among those that did not ovulate in response to the first $\mathrm{GnRH}$ injection. A similar tendency was observed in cows subjected to the 5-d timed AI program (Bisinotto et al., 2013).

In many countries, the dairy industry has been continuously consolidating, and larger herds likely require more population-driven approaches to improve reproduction. Adequate transition cow management is essential to reduce incidence of diseases and expedite resumption of ovulation postpartum, all of which have a profound effect on reproductive performance (Santos et al., 2009, 2010). Nevertheless, the strategic use of interventions such as identifying low-fertility subpopulations that respond to therapy will likely become more important in the future to improve $\mathrm{P} / \mathrm{AI}$ on dairy farms. As previously observed in cows subjected to the 5-d timed AI program (Bisinotto et al., 2013), the current results indicate that a single ultrasound examination of the ovaries performed at initiation of the Ovsynch protocol effectively identified a low-fertility population based on the absence of CL. Even in herds that apply concepts of transition cow management to minimize peripartum problems, approximately $30 \%$ of the cows receiving the first AI postpartum are anovular (Stevenson et al., 2008; Bisinotto et al., 2010). In addition, based on the day when resynchronization is initiated, 22 to $46 \%$ of cows might not have a CL, either because they became anovular or simply because, on the day of the estrous cycle (Fricke et al., 2003; Silva et al., 2009), they are either anovular or not in diestrus when the Ovsynch protocol is initiated. The therapeutic approach of treating cows without CL with 2 intravaginal inserts to increase progesterone concentrations above $2.0 \mathrm{ng} / \mathrm{mL}$ 
restored $\mathrm{P} / \mathrm{AI}$ similar to that of observed for cows in diestrus. This strategy allows for targeted progesterone supplementation with a suitable dose that optimizes $\mathrm{P} /$ AI in populations of cows that would otherwise show low fertility.

A comprehensive economic evaluation of the use of 2 CIDR inserts in cows without CL at the initiation of the timed AI program needs to be performed. The average value of a pregnancy in the United States varies, but De Vries (2006) estimated it to be $\$ 278$. For every 100 cows to be enrolled in a timed AI protocol, 27 are expected to not have a CL based on the prevalence of the current study. If this cohort is treated, P/AI increases by 8.3 percentage units, from 28.9 to $37.2 \%$. Therefore, for every 27 cows without CL, the number of pregnancies would be 7.8 in CON compared with 10 in 2CIDR. These 2.2 extra pregnancies represent approximately $\$ 612$, which has to offset the costs of the inserts and the labor involved. For 27 treated cows in the United States, the costs would be between $\$ 230$ and $\$ 450$ if the insert is used twice (Cerri et al., 2009a) or only once. Under both scenarios, an economic benefit would be expected. Compared with inserting 2 devices, a delivery system that releases at least twice the amount of progesterone as the currently available device would be ideal to target high-producing dairy cows without a CL.

\section{CONCLUSIONS}

Supplementing progesterone with 2 intravaginal inserts increased concentrations in plasma to $2.77 \mathrm{ng} /$ $\mathrm{mL}$ and restored $\mathrm{P} / \mathrm{AI}$ in lactating dairy cows lacking $\mathrm{CL}$ at the initiation of the Ovsynch protocol. Moreover, P/AI for cows without CL treated with exogenous progesterone was similar to that of cows in diestrus, indicating that the supplementation strategy used in the present study was effective in reestablishing fertility in a population of cows subfertile because of anovulation or simply not being in diestrus when the timed AI protocol is initiated. The increase in $\mathrm{P} / \mathrm{AI}$ in response to progesterone supplementation was not associated with changes in synchrony of the estrous cycle or diameter of the ovulatory follicle. The benefits of supplemental progesterone to cows without CL were observed primarily in cows that did not ovulate to the initial GnRH of the Ovsynch protocols and those not detected in estrus at AI. Collectively, these data indicate that incorporation of 2 CIDR inserts during the Ovsynch protocol in cows without a CL increases progesterone concentrations and reestablishes $\mathrm{P} / \mathrm{AI}$ similar to that of cows in diestrus. A concentration of progesterone of $2.0 \mathrm{ng} / \mathrm{mL}$ throughout the final stages of development of the preovulatory follicle seems to be the minimum needed to result in $\mathrm{P} / \mathrm{AI}$ comparable to that of cows in diestrus. A single ultrasound examination of the ovaries at the beginning of the Ovsynch protocol is effective in identifying subfertile cows and allows for a selective treatment with adequate progesterone to improve $\mathrm{P} /$ AI.

\section{ACKNOWLEDGMENTS}

The authors thank the owners and staff of Alliance Dairies (Trenton, FL), River Ranch Farms (Hanford, CA), John de Jong Dairy (Hanford, CA), and High Roller Dairy (Hanford, CA) for the use of their cows and facilities and assistance during experimental procedures. The assistance of Eduardo S. Ribeiro, Fábio S. Lima, Gabriel C. Gomes, Rodolfo D. Medina, and Thiago F. Fabris from the University of Florida (Gainesville) is appreciated. Financial support for this project was provided by a grant from the Southeast Milk Inc. Checkoff Program (Belleview, FL).

\section{REFERENCES}

Anderson, L. H., and M. L. Day. 1994. Acute progesterone administration regresses persistent dominant follicles and improves fertility of cattle in which estrus was synchronized with melengestrol acetate. J. Anim. Sci. 72:2955-2961.

Bisinotto, R. S., R. C. Chebel, and J. E. P. Santos. 2010. Follicular wave of the ovulatory follicle and not cyclic status influences fertility of dairy cows. J. Dairy Sci. 93:3578-3587.

Bisinotto, R. S., I. J. Lean, W. W. Thatcher, and J. E. P. Santos. 2015. Meta-analysis of progesterone supplementation during timed AI programs in dairy cows. J. Dairy Sci. 98:2472-2487. http:// dx.doi.org/10.3168/jds.2014-8954.

Bisinotto, R. S., E. S. Ribeiro, F. S. Lima, N. Martinez, L. F. Greco, L. F. Barbosa, P. P. Bueno, L. F. Scagion, W. W. Thatcher, and J. E. P. Santos. 2013. Targeted progesterone supplementation improves fertility in lactating dairy cows without a corpus luteum at the initiation of the timed artificial insemination protocol. J. Dairy Sci. 96:2214-2225.

Bisinotto, R. S., E. S. Ribeiro, and J. E. P. Santos. 2014. Synchronisation of ovulation for management of reproduction in dairy cows. Animal 8:151-159.

Bisinotto, R. S., and J. E. P. Santos. 2011. The use of endocrine treatments to improve pregnancy rates in cattle. Reprod. Fertil. Dev. $24: 258-266$.

Bleach, E. C., R. G. Glencross, and P. G. Knight. 2004. Association between ovarian follicle development and pregnancy rates in dairy cows undergoing spontaneous oestrous cycles. Reproduction 127:621-629.

Brusveen, D. J., A. P. Cunha, C. D. Silva, P. M. Cunha, R. A. Sterry, E. P. Silva, J. N. Guenther, and M. C. Wiltbank. 2008. Altering the time of the second gonadotropin-releasing hormone injection and artificial insemination (AI) during Ovsynch affects pregnancies per AI in lactating dairy cows. J. Dairy Sci. 91:1044-1052.

Cerri, R. L., R. C. Chebel, F. Rivera, C. D. Narciso, R. A. Oliveira, M. Amstalden, G. M. Baez-Sandoval, L. J. Oliveira, W. W. Thatcher, and J. E. P. Santos. 2011. Concentration of progesterone during the development of the ovulatory follicle: II. Ovarian and uterine responses. J. Dairy Sci. 94:3352-3365.

Cerri, R. L., H. M. Rutigliano, R. G. Bruno, and J. E. P. Santos. 2009a. Progesterone concentration, follicular development and induction of cyclicity in dairy cows receiving intravaginal progesterone inserts. Anim. Reprod. Sci. 110:56-70. 
Cerri, R. L., H. M. Rutigliano, R. C. Chebel, and J. E. P. Santos. 2009b. Period of dominance of the ovulatory follicle influences embryo quality in lactating dairy cows. Reproduction 137:813-823.

De Vries, A. 2006. Economic value of pregnancy in dairy cattle. J. Dairy Sci. 89:3876-3885.

Denicol, A. C., G. Lopes Jr., L. G. Mendonça, F. A. Rivera, F. Guagnini, R. V. Perez, J. R. Lima, R. G. Bruno, J. E. P. Santos, and R. C. Chebel. 2012. Low progesterone concentration during the development of the first follicular wave reduces pregnancy per insemination of lactating dairy cows. J. Dairy Sci. 95:1794-1806.

Endo, N., K. Nagai, T. Tanaka, and H. Kamomae. 2012. Comparison between lactating and non-lactating dairy cows on follicular growth and corpus luteum development, and endocrine patterns of ovarian steroids and luteinizing hormone in the estrous cycles. Anim. Reprod. Sci. 134:112-118.

Ferguson, J. D., D. T. Galligan, and N. Thomsen. 1994. Principal descriptors of body condition score in Holstein cows. J. Dairy Sci. 77:2695-2703.

Folman, Y., M. Rosenberg, Z. Herz, and M. Davidson. 1973. The relationship between plasma progesterone concentration and conception in post-partum dairy cows maintained on two levels of nutrition. J. Reprod. Fertil. 34:267-278.

Fonseca, F. A., J. H. Britt, B. T. McDaniel, J. C. Wilk, and A. H. Rakes. 1983. Reproductive traits of Holsteins and Jerseys. Effects of age, milk yield, and clinical abnormalities on involution of cervix and uterus, ovulation, estrous cycles, detection of estrus, conception rate, and days open. J. Dairy Sci. 66:1128-1147.

Fricke, P. M., D. Z. Caraviello, K. A. Weigel, and M. L. Welle. 2003. Fertility of dairy cows after resynchronization of ovulation at three intervals following first timed insemination. J. Dairy Sci. 86:3941-3950

Gümen, A., J. N. Guenther, and M. C. Wiltbank. 2003. Follicular size and response to Ovsynch versus detection of estrus in anovular and ovular lactating dairy cows. J. Dairy Sci. 86:3184-3194.

Lima, J. R., F. A. Rivera, C. D. Narciso, R. Oliveira, R. C. Chebel, and J. E. P. Santos. 2009. Effect of increasing amounts of supplemental progesterone in a timed artificial insemination protocol on fertility of lactating dairy cows. J. Dairy Sci. 92:5436-5446.

Macmillan, K. L., V. K. Taufa, D. R. Barnes, and A. M. Day. 1991. Plasma progesterone concentrations in heifers and cows treated with a new intravaginal device. Anim. Reprod. Sci. 26:25-40.

Rathbone, M. J., C. R. Bunt, C. R. Ogle, S. Burggraaf, K. L. Macmillan, C. R. Burke, and K. L. Pickering. 2002. Reengineering of a commercially available bovine intravaginal insert (CIDR insert) containing progesterone. J. Control. Release 85:105-115.

Revah, I., and W. R. Butler. 1996. Prolonged dominance of follicles and reduced viability of bovine oocytes. J. Reprod. Fertil. 106:39-47.
Rivera, F. A., L. G. Mendonça, G. Lopes Jr., J. E. P. Santos, R V. Perez, M. Amstalden, A. Correa-Calderon, and R. C. Chebel. 2011. Reduced progesterone concentration during growth of the first follicular wave affects embryo quality but has no effect on embryo survival post transfer in lactating dairy cows. Reproduction 141:333-342.

Santos, J. E. P., R. S. Bisinotto, E. S. Ribeiro, F. S. Lima, L. F. Greco, C. R. Staples, and W. W. Thatcher. 2010. Applying nutrition and physiology to improve reproduction in dairy cattle. Soc. Reprod. Fertil. Suppl. 67:387-403

Santos, J. E. P. H. M. Rutigliano, and M. F. Sá Filho. 2009. Risk factors for resumption of postpartum estrous cycles and embryonic survival in lactating dairy cows. Anim. Reprod. Sci. 110:207-221.

Sartori, R., J. M. Haughian, R. D. Shaver, G. J. Rosa, and M. C. Wiltbank. 2004. Comparison of ovarian function and circulating steroids in estrous cycles of Holstein heifers and lactating cows. J. Dairy Sci. 87:905-920.

Shaham-Albalancy, A., Y. Folman, M. Kaim, M. Rosenberg, and D. Wolfenson. 2001. Delayed effect of low progesterone concentrations on bovine uterine $\mathrm{PGF}_{2 \alpha}$ secretion in the subsequent oestrous cycle. Reproduction 122:643-648.

Shaham-Albalancy, A.. A. Nyska, M. Kaim, M. Rosenberg, Y. Folman, and D. Wolfenson. 1997. Delayed effect of progesterone on endometrial morphology in dairy cows. Anim. Reprod. Sci. 48:159-174.

Silva, E., R. A. Sterry, D. Kolb, N. Mathialagan, M. F. McGrath, J. M. Ballam, and P. M. Fricke. 2009. Effect of interval to resynchronization of ovulation on fertility of lactating Holstein cows when using transrectal ultrasonography or a pregnancy-associated glycoprotein enzyme-linked immunosorbent assay to diagnose pregnancy status. J. Dairy Sci. 92:3643-3650.

Stevenson, J. S., D. E. Tenhouse, R. L. Krisher, G. C. Lamb, J. E. Larson, C. R. Dahlen, J. R. Pursley, N. M. Bello, P. M. Fricke, M. C. Wiltbank, D. J. Brusveen, M. Burkhart, R. S. Youngquist, and H. A. Garverick. 2008. Detection of anovulation by heatmount detectors and transrectal ultrasonography before treatment with progesterone in a timed insemination protocol. J. Dairy Sci. 91:2901-2915

Wiltbank, M. C., A. H. Souza, P. D. Carvalho, R. W. Bender, and A. B. Nascimento. 2011. Improving fertility to timed artificial insemination by manipulation of circulating progesterone concentrations in lactating dairy cattle. Reprod. Fertil. Dev. 24:238-243.

Xu, Z. Z., L. J. Burton, and K. L. Macmillan. 1997. Reproductive performance of lactating dairy cows following estrus synchronization regimens with PGF2alpha and progesterone. Theriogenology $47: 687-701$. 